\title{
CORROSION RELIABILITY PREDICTION: LONG TERM NUCLEAR WASTE STORAGE IN YUCCA MOUNTAIN
}

\author{
G. S. Frankel, Eiji Tada, B. Maier \\ Fontana Corrosion Center, The Ohio State University \\ Columbus, OH 43210, USA
}

\begin{abstract}
The U.S. Department of Energy has proposed the disposal of high level nuclear waste from commercial and defense reactors in a mined geologic repository under Yucca Mountain, Nevada. The waste will be stored in metallic canisters. The barrier against corrosion will be an Alloy 22 canister and a Ti Grade 7 drip shield. Both of these materials are extremely corrosion resistant. The environment inside Yucca Mountain is relatively benign, but the long time period over which these materials must resist penetration makes corrosion a concern. This paper presents a background of the corrosion issues and shows some recent results regarding measurements of localized corrosion under thin aqueous layers and layers that simulate wet dust deposits.
\end{abstract}

Keywords: Nuclear waste storage, Ni-based alloys, stainless steel, localized corrosion

\section{Introduction}

High level radioactive waste and spent nuclear fuel from commercial nuclear power plants and weapons plants is accumulating in the U.S. and in many countries around the world. Currently, waste generated in the U.S. is being held in temporary storage at 70 power plants in 33 states. In 1982 the U.S. Congress passed the Nuclear Waste Policy Act, which mandates the permanent disposal of this waste in an underground mined geologic repository. Nine sites were initially investigated, and in 1987 the Nuclear Waste Policy Act was amended to direct the U.S. Department of Energy to focus its efforts on studying one site, Yucca Mountain, Nevada. In 2002, Congress approved DOE's recommendation of Yucca Mountain as the site for the waste repository, and the resolution was signed by President Bush. Detailed background material on nuclear waste, waste disposal, and Yucca Mountain is available at the DOE website [1].

Some of the radionuclides in the waste have extremely long lifetimes, so a permanent disposal site must maintain its integrity for a long time, on the order of thousands of years to as long as a million years. Any critical component made from metal must therefore resist corrosion over a very long time period and interesting corrosion issues must be addressed. Of course, for any corrosion problem, one must consider both the materials and the environment, and these issues are addressed here. More detailed information describing the materials in the current design and the environment at Yucca Mountain can be found at the Nuclear Waste Technical Review Board website [2]. Lifetime prediction requires some sort of framework, and this will be addressed in a subsequent section. This paper will end with some recent results related to localized corrosion under thin electrolyte layers.

\section{Environment}

Yucca Mountain is in Nye County, Nevada, which is about $100 \mathrm{mi}$ northwest of Las Vegas. The advantages of the site are its dry climate, remoteness, stable geology, deep water table, and closed water basin. [2] This desert region receives very little precipitation, most of which evaporates or runs off of the mountain. However, some of the moisture enters into the mountain and is transported downwards to the water table. The repository will be located about $300 \mathrm{~m}$ above the water table and $300 \mathrm{~m}$ below the surface, in what is known as the unsaturated zone. The rock in Yucca Mountain is volcanic tuff, which contains some pores and fractures that allow water to be stored and transported.

The waters associated with Yucca Mountain have been analyzed. Both the water in the rock pores and the water under the water table are dilute and neutral natural waters containing 
carbonate, sulfate, nitrate, chloride, and fluoride anions and sodium, calcium, potassium and magnesium cations with concentration on the order of $\mathrm{mg} / \mathrm{L}$ to hundreds $\mathrm{of} \mathrm{mg} / \mathrm{L}$. [2] These waters are extremely benign from a corrosion point of view. Of particular note is the relatively high concentration of nitrate, which can be an effective corrosion inhibitor. However, these dilute waters can become concentrated as the result of evaporation of water on hot surfaces, such as drip shields and waste packages.

The radioactive waste will be a source of heat that will create one long thermal gradient [2]. The repository will stay cool prior to closure because of ventilation during the period of waste emplacement. However, it is planned to close and seal the repository when it is full, which will result in an increase in temperature near the waste canisters. Depending upon design details, the maximum temperature might be only $80^{\circ} \mathrm{C}$ or as much as $170^{\circ} \mathrm{C}$. [2] The heat up period will take decades, and the cool down period will take as much as 100,000 years. When the metals are so hot that the local temperature is above the boiling point of any solution that might form, corrosion will not be possible. Furthermore, localized corrosion will not occur below a critical temperature that is on the order of $90^{\circ} \mathrm{C}$ for the corrosion resistant alloys to be used in the waste package. Therefore, corrosion is only a concern during a period when the temperature is in an intermediate range that is still relatively hot, but where an aqueous phase is possible.

The proposed repository at Yucca Mountain should never be in a condition such that it is immersed under a bulk liquid. There are two possible scenarios for the development of an aggressive electrolyte that might cause corrosion. [2] It is possible for water to drip on the waste package after the surrounding rock cools below the boiling point. This assumes failure of the drip shield that is included as part of the design to deflect dripping water away from the waste package. If water does drip on the package, it is possible for the package to be at a higher temperature than the rock from which the water dripped because of thermal gradients in the repository. This will lead to evaporation of the water and precipitation of the dissolved minerals if the temperature is high enough, or to a concentrated brine solution at lower temperatures. Another scenario is possible even if there are no drips directly on the package. The humidity in the air can interact with rock and other dust on the waste package surface and deliquesce to create what can be called a deliquescence brine layer.

The concentration of species dissolved into the final environment that will be in contact with the waste package will depend on the solubility of the various species present in the original water as a function of temperature [2]. However, it is possible for thin concentrated electrolyte layers to exist on the metallic surfaces. If those environments are aggressive enough, for instance as the result of enrichment of chloride ions and insufficient inhibition by other ions, and if the temperature is high enough, then corrosion of metals is possible.

\section{Materials}

The current design for the waste package includes an outer canister to be fabricated from Alloy 22 , which is a Ni-based alloy containing about $22 \% \mathrm{Cr}, 13 \% \mathrm{Mo}$, and $3 \% \mathrm{~W}$. [3-5] This alloy is one of the most corrosion resistant alloys available today. It is resistant to all forms of corrosion, but will suffer localized corrosion under extremely corrosive conditions.

As mentioned above, the current design calls for the cylindrical waste packages to be covered by a drip shield that is designed to deflect dripping water away from the waste package surface. These drip shields are to be made from Ti Grade 7, which is a Pd-containing alloy that is also extraordinarily resistant to localized corrosion, but the Ti alloy can suffer from stress corrosion cracking. [6]

\section{Framework for Prediction of Localized Corrosion}


The rate of material consumption from Alloy 22 passive dissolution is insufficient by a large margin to result in penetration of the thick metal canister even after very long times. For penetration to occur, the passive film will need to be breached. Alloy 22 is very resistant to localized corrosion, though crevice corrosion is more likely than pitting corrosion. The rates of localized corrosion are certainly large relative to passive dissolution, though it is still not clear if localized corrosion can be sustained to the extent that it would penetrate the package.

One might make the assumption that any amount of localized corrosion is problematic given the possibility for high rates of localized corrosion propagation. One approach to considering localized corrosion in a lifetime assessment is to design a structure such that localized corrosion would never occur. It is reasonable to expect that localized corrosion will never occur if one could be sure that the corrosion potential stayed below the lowest critical potential, which would be the repassivation potential for a material with a deep active crevice corrosion site [7].

The Yucca Mountain Project has developed a model to predict the performance of the system and the release of radionuclides called the Total System Performance Assessment [1]. This model includes many different modules to describe transport and material degradation. Details of this model are beyond the scope of this review, but they can be found in reports that are available online. [1]

\section{Corrosion under Artificial Deliquescence Brine Layers}

As mentioned above, the waste packages will never be immersed in a bulk aqueous electrolyte, but might be exposed to thin layers, perhaps containing particulate from rock dust, that could be aggressive. Most corrosion studies in thin aqueous layers have been associated with atmospheric corrosion of materials such as iron and zinc. There have been very few studies of the behavior of corrosion resistant alloys (passive metals) under thin aggressive layers. [8] In this part of the work, we have attempted to generate, in a reproducible and controllable fashion, the artificial deliquescence brine layers to represent the layers that might form on waste packages.

Electrophoretic deposition (EPD) was used to create simulated dust layers on 304 stainless steel (SS) surfaces. EPD is a very useful technique to deposit ceramic particles on metal surfaces; thick layers on the order of $\mu \mathrm{m}$ to $\mathrm{mm}$ can be obtained by EPD. [9] The thickness of the layers can be controlled easily by changing applied voltage and deposition time.

Silica particles were prepared by hydrolysis of tetraethoxysilane (TEOS) in the presence of sodium dodecyl sulfate (SDS) as a dispersant, following the procedure described by Nishimori et al. [10] The silica particles obtained in this study were monodispersed, with diameter about 350 to $400 \mathrm{~nm}$. The silica suspension for EPD was a mixture of $\mathrm{H}_{2} \mathrm{O}$ and ethyl alcohol (EtOH) containing $2 \mathrm{wt} \%$ silica particles. The mole ratio of $\mathrm{H}_{2} \mathrm{O}$ and EtOH was $1: 10$. The mixture also contained $0.01 \mathrm{wt} \%$ polyethylenimine (PEI). [11] PEI is a cationic polyelectrolyte that can cause a considerable shift of silica particle isoelectric point. [10] The 304 SS substrate was polished to 600 grit and then rinsed with EtOH before deposition. EPD was carried out cathodically on substrates at the voltage of $29 \mathrm{~V}$.

Figure 1 shows a SEM image of a sample with a silica layer a couple of $\mu \mathrm{m}$ in thickness that was obtained by a deposition for $5 \mathrm{~s}$ at $29 \mathrm{~V}$. The surface of the silica layer looks very homogeneous and is composed of very fine particles packed densely. The silica layer thickness increased up to about $60 \mu \mathrm{m}$ with increasing deposition time. Layers thicker than $60 \mu \mathrm{m}$ delaminated from the substrates due to shrinkage during drying of the solvent of the suspension. A droplet of water placed on the edge of a silica layer was soaked up quickly and the contact angle seemed to be almost 0 degrees. Even after an atmospheric corrosion experiment, silica 
layers made by EPD were still intact. In addition, pitting corrosion initiated under the silica layers. These results indicate that silica layers made by EPD can be used as a suitable host layer for deliquescence brine.

Cathodic polarization curves were measured on 304SS substrates coated with silica layers of different thickness and an uncoated sample as reference in a stagnant bulk solution of $0.1 \mathrm{M}$ $\mathrm{NaCl}$. The limiting current region of oxygen reduction reaction was seen in the potential range from -0.4 to $-0.8 \mathrm{~V}$ vs. SSE in the curves for silica-coated samples. At more active potentials, a current increase due to hydrogen evolution reaction was observed in all the curves. Cathodic polarization behavior for the silica-coated samples was almost the same as for the uncoated sample. The limiting current decreased with increasing in the film thickness of a silica layer, as shown in Figure 2. Anodic polarization curves measured on similar samples indicated that the breakdown potential did not depend on the thickness of a silica layer. These results demonstrate that in bulk electrolyte solutions the silica layer acts as a barrier layer for diffusion of dissolved oxygen but not for localized corrosion.

To investigate the effect of a silica layer on localized corrosion behavior under atmospheric corrosion environments, the open circuit potential (OCP) was measured during drying of a layer of $0.5 \mathrm{M} \mathrm{MgCl}_{2}$. The initial thickness of $\mathrm{MgCl}_{2}$ was $500 \mu \mathrm{m}$ and relative humidity around the sample was controlled with a reservoir of saturated $\mathrm{MgCl}_{2}$. The OCP transients were measured by the method described by Vera Cruz et al. [8] As shown in Fig. 3, the initiation of pitting corrosion was associated with an abrupt decrease in OCP in the active direction. The time for pitting to initiate did depend on $\mathrm{SiO}_{2}$ layer thickness. Before pitting corrosion took place, the OCP transient for the silica-coated sample was almost the same as that for the uncoated sample under the drying with saturated $\mathrm{MgCl}_{2}$. However the OCP transient for the silica-coated samples showed slower decay compared with the uncoated sample after pitting corrosion initiated. The similar trend was observed under the drying with saturated $\mathrm{LiCl}$, although pitting corrosion initiated earlier due to the difference in drying rate. These results indicate that the silica layer might not influence pit initiation but might retard pit growth.

\section{Electrochemical Measurements under Thin Aqueous Layers}

Measurements were also made on stainless steel under aqueous layers with thickness down to about $5 \mu \mathrm{m}$ using a Kelvin Probe as a means to measure and control the potential. Stratmann has shown that the Kelvin Probe provides a non-contact measure of the corrosion potential, and that rewiring of the standard Kelvin Probe results in a Kelvin Probe potentiostat that controls as well as measures the potential. [12-13] The advantage of this approach is that it is totally noncontact and accurate, with no disruption of the thin layer and no addition of extraneous ions to the layer.

The working electrode was a $1 \mathrm{~mm}$ diameter 304 stainless steel wire that was embedded in epoxy to expose the cross section. The counter electrode was a tube that also embedded in the epoxy and was thus co-planar with the working electrode. Its cross section was a disk that surrounded the working electrode much like a ring-disk electrode. The counter electrode was made from different materials in different samples, including graphite, Inconel 600, Incoloy 800 , and gold. The vibrating reference electrode, a piece of the same $304 \mathrm{SS}$, was calibrated using $\mathrm{Cu} / \mathrm{CuSO}_{4}$.

A fixed volume of $0.7 \mathrm{M} \mathrm{NaCl}$ solution was applied to the surface to create a thin layer and allowed to equilibrate with the environment in the Kelvin Probe chamber, which was air with a relative humidity maintained at about $95 \%$. At this humidity, the equilibrium concentration is about $1 \mathrm{M}$, so the $0.7 \mathrm{M} \mathrm{NaCl}$ solution lost water and the layer became thinner. Electrochemical measurements were initiated after the thin solution reached a stabile thickness, 
which took a couple of hours. The potential was scanned from the corrosion potential either in the anodic direction at a nominal rate of $1 \mathrm{mV} / \mathrm{s}$ or in the cathodic direction at a nominal rate of $0.33 \mathrm{mV} / \mathrm{s}$.

Cathodic polarization curves showed clear evidence of a diffusion limited current density for oxygen reduction followed by hydrogen evolution. As was observed previously for $\mathrm{Fe}$ and $\mathrm{Pt}$ electrodes [13-14], the oxygen reduction limiting current density on 304L SS varies inversely with electrolyte layer thickness only over a range of thickness. Figure $4 a$ and $b$ show that there is deviation from for both thick layers (greater than about $300 \mu \mathrm{m}$ ) and for thin layers (less than about $12 \mu \mathrm{m}$ ). The deviation for thick layers is caused by natural convection in the droplet (perhaps aided by an oscillating pressure associated with the vibrating Kelvin Probe) and the deviation for thin layers is caused by the kinetic limitation of oxygen crossing the air/electrolyte interface.

Anodic polarization curves exhibited passivity, metastable pitting in some cases, and breakdown. Owing to limitations in the electronics, the current was limited to $15 \mu \mathrm{A}$, which is equivalent to only about $2 \mathrm{~mA} / \mathrm{cm}^{2}$. One interesting observation is the phenomenon shown in Figure 5. Figure 5a shows the Kelvin Probe wire, which was vibrated over the sample of the same diameter. A reflection of the bottom of the vibrating electrode can be seen in the thin layer of electrolyte that covered the sample. Though it is hard to see, the counter electrode is a ring around the working electrode, the space separating them being filled with epoxy. After pit initiation, a number of observations were evident using a binocular telescope to magnify the view of the electrode in the Kelvin Probe chamber. First, a shower of bubbles associated with hydrogen evolution could be seen (though not in Figure 5) at the inner edge of the counter electrode. After a few minutes of pit growth, a "crease" in the electrolyte formed at a location between the working and counter electrodes, Figure $5 \mathrm{~b}$. With time, the electrolyte layer inside this crease increased in volume, eventually becoming hundreds of time larger than the original volume of the electrolyte before the test, Figure 5c. As pitting progressed and cations dissolved rapidly into the thin film electrolyte, the concentration of the electrolyte was no longer in equilibrium with the $95 \% \mathrm{RH}$ in the chamber, and water was taken from the air into the electrolyte. This happened quickly, over a period of minutes. The implication of this observation is that a thin electrolyte layer does not exert an inhibiting influence on localized corrosion growth once initiated. In fact, the thin layer can take up moisture from the air to become essentially a bulk electrolyte drop.

\section{Summary}

Some issues regarding the long term prediction of corrosion in a repository at Yucca Mountain, Nevada were presented. The materials and environments were discussed and some preliminary results from studies on the behavior of a passive metal, $304 \mathrm{SS}$, were presented. Thin layers of $\mathrm{SiO}_{2}$ particles, which might represent dust particles on a waste package, were deposited, and found to affect both the limiting current density for oxygen reduction and aspects of pit growth. Measurements made on 304 SS under thin layers of electrolyte using a Kelvin Probe potentiostat found that the limiting current density for oxygen reduction was proportional to the electrolyte layer thickness only over a certain range of thickness. After pit initiation under thin film electrolyte layers, water uptake from a humid atmosphere resulted in the formation of a large droplet of solution. These results are preliminary and the phenomena will be studied further.

\section{Acknowledgments}

Support by the Office of Science and Technology International of the U.S. Department of Energy, Office of Civilian Radioactive Waste Management is gratefully acknowledged. 


\section{References}

1. DOE Office of Civilian Radioactive Waste Management website, http://www.ocrwm.doe.gov/ymp.

2. Nuclear Waste Technical Review Board website, http://www.nwtrb.gov.

3. Kenneth J. Evans, Ahmet Yilmaz, S. Daniel Day, Lana L. Wong, John C. Estill, and Raúl B. Rebak, J. Metals, 57 (2005) p. 56.

4. B.A. Kehler, G.O. Ilevbare, and J.R. Scully, Corrosion, 57 (2001), p. 1042.

5. D.S. Dunn, Y.-M. Pan, K.T. Chiang, L. Yang, G.A. Cragnolino, and X. He., J. Metals, 57 (2005) p 49.

6. Fred Hua, Kevin Mon, Pasu Pasupathi, Gerald Gordon, and David Shoesmith, J. Metals, 57 (2005) p. 20.

7. J. H. Payer, J. A. Beavers, T. M. Devine, Jr., G. S. Frankel, R. H. Jones, R. G. Kelly, R. M. Latanision, "Final Report, Waste Package Materials Performance Peer Review Panel," Report to DOE, 2002.

8. R.P. Vera Cruz, A. Nishikata, and T. Tsuru, Corr. Sci., 40 (1998) p. 125.

9. I. Zhitomirsky, Adv Colloid Interface Sci., 97 (2002) p. 279.

10. H. Nishimori, M. Tatsumisago, and T. Minami, J. Sol-Gel Sci. Technol., 9 (1997) p. 25.

11. K. Hasegawa, M. Tatsumisago, and T. Minami, J. Ceram. Soc. Japan, 105 (1997) p. 569.

12. M. Stratmann, and H. Streckel, Corr. Sci., 30, (1990) p. 681.

13. M. Stratmann, H. Streckel, K.T. Kim, and S. Crockett, Corr. Sci., 30, (1990) p. 715.

14. A. Nishikata, Y. Ichihara, Y. Hayashi, and T. Tsuru, J. Electrochem. Soc. 144 (1997) p. 1244. 


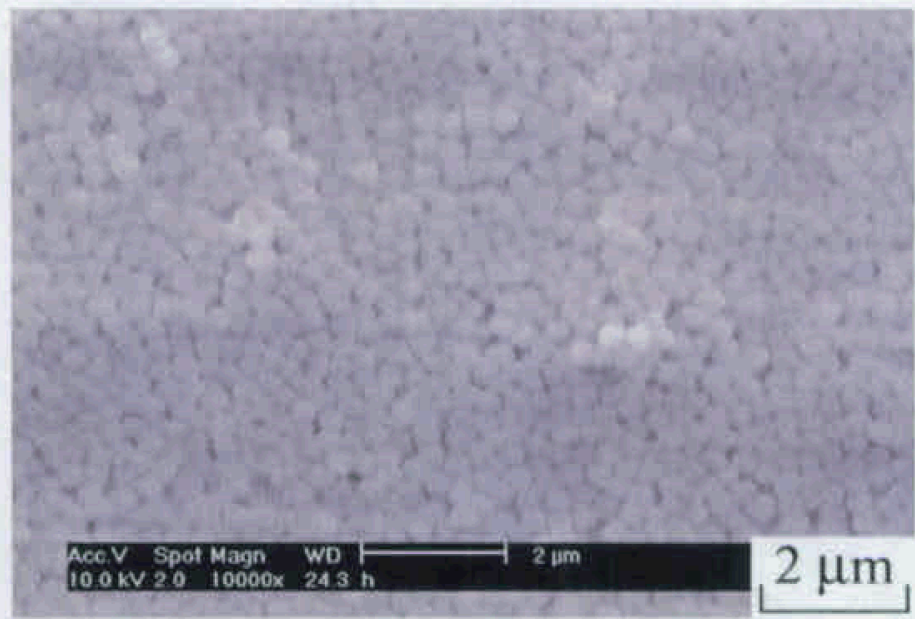

Figure 1. SEM image of $\mathrm{SiO}_{2}$ layer deposited for $5 \mathrm{~s}$ on SS.

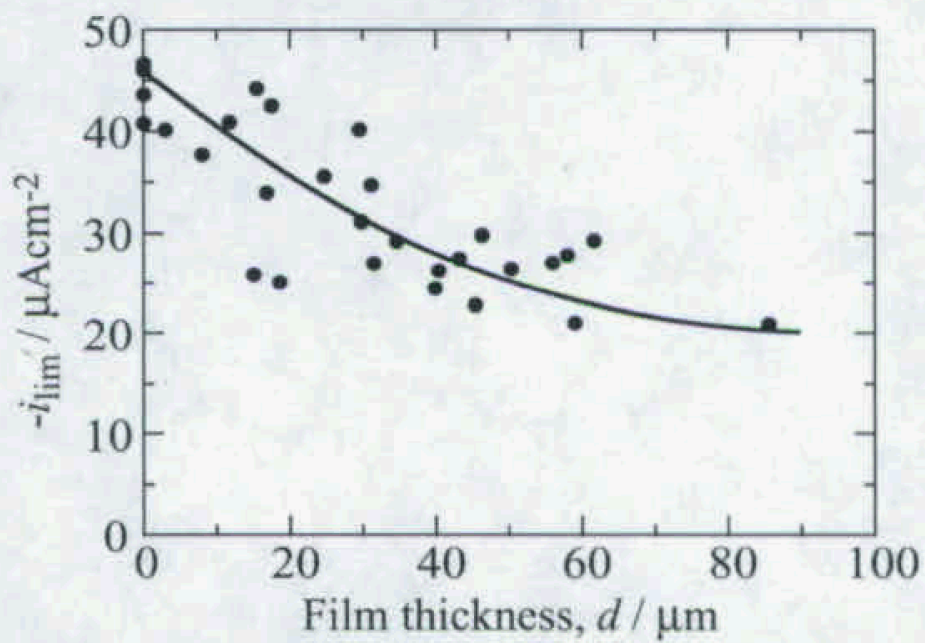

Figure 2. Limiting current density for oxygen reduction reaction for $304 \mathrm{SS}$ coated with $\mathrm{SiO}_{2}$ layers of varying thickness in stagnant solutions of $0.1 \mathrm{M} \mathrm{NaCl}$

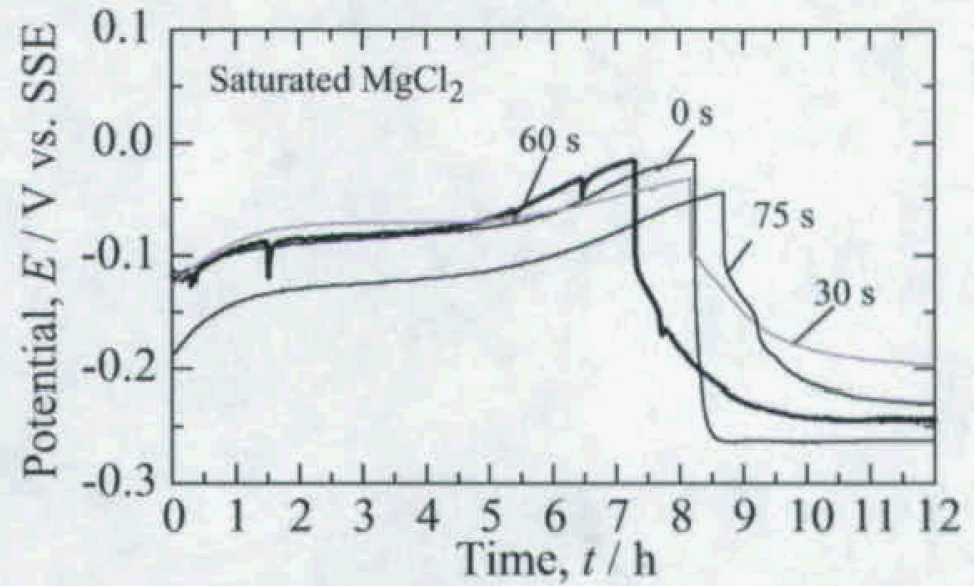

Figure 3. OCP transients for $304 \mathrm{SS}$ samples with $\mathrm{SiO}_{2}$ layers having varying thickness (thickness increased with increasing deposition time, which is given in the figure) during drying of $0.5 \mathrm{M} \mathrm{MgCl}_{2}$ thin layer as a function of drying time. The initiation of pitting is accompanied by a sharp drop in potential. 

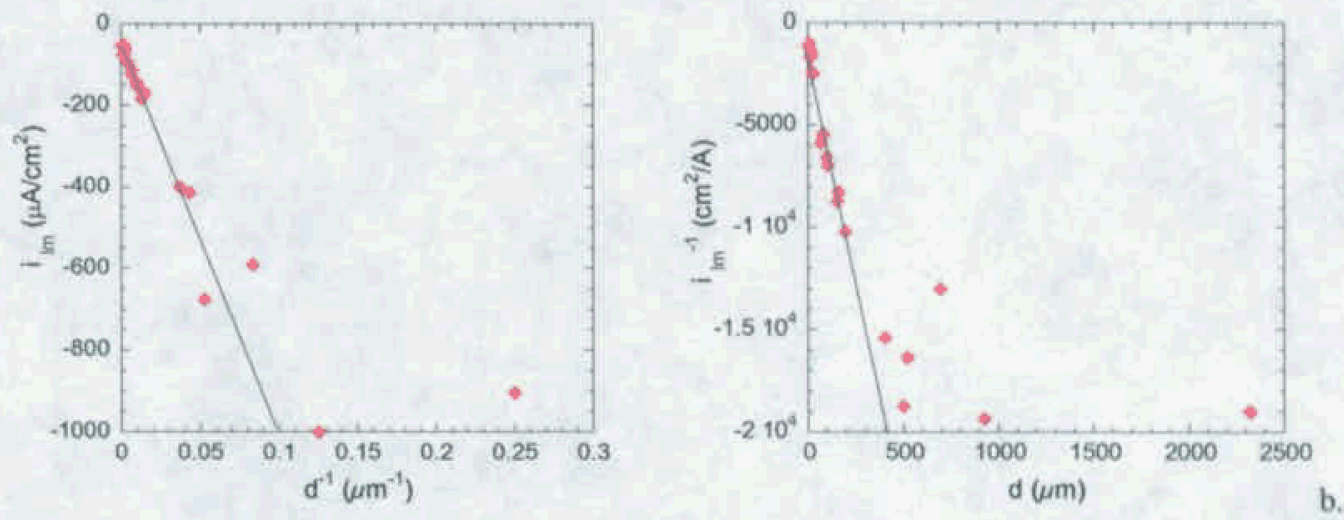

a.

Figure 4. Oxygen reduetion limiting current on SS in $1 \mathrm{M} \mathrm{NaCl}$ layers of different thickness. a) and b) are the same data plotted differently to show the deviation in Fickian behavior at thin and thick layers, respectively.

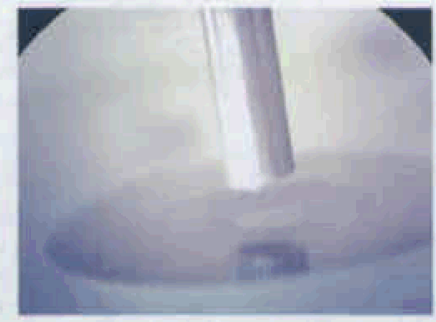

a.

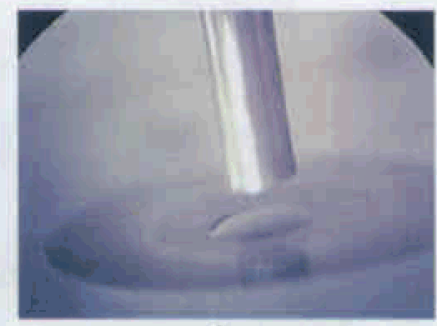

b.

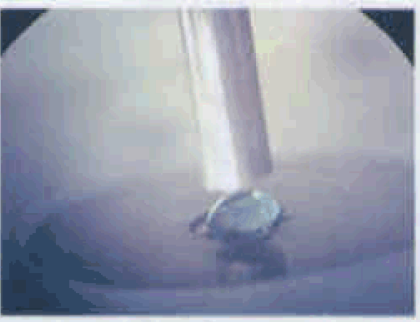

C.

Figure 5. Images of the Kelvin Probe and sample during anodic polarization after pit initiation. a) just as a pit initiated b) showing a "crease" in the electrolyte associated with corrosion product formation c) large droplet formed by absorption of water from the humid air. 